\title{
Assessing the Efficacy of RoboTeach Extension Project on Public School Teachers
}

\author{
${ }^{1}$ Michelle C. Gonzales, ${ }^{2}$ Edilberto Z. Andal, ${ }^{3}$ Delon A. Ching, \\ ${ }^{3}$ Magdalena P. Gaffud \& ${ }^{3}$ Eudora C. Tabo
}

\begin{abstract}
The integration of robotics in the education was one of the aspirations of the K-12 institution in the Philippines. The RoboTeach Extension Project was established to address the challenges associated with the implementation of robotics in K-12 education. This study explores the teachers' perception of the efficacy in the implementation of the project which focused on training the Department of Education (DepEd) teachers in San Pablo City Laguna, Philippines on the basic concepts and applications of robotics and automation. The topics and learning activities covered during the ten-day training were based on the self-assessment survey results on the level of knowledge of teachers. The study used a descriptive method of research using a quantitative approach and adopted the LSPU Extension Services Evaluation Survey Questionnaire to determine the respondents' perception of the level of project efficacy. The data were obtained from twenty-five DepEd teachers and analyzed using descriptive statistics such as frequency count, per cent, weighted mean and ANOVA. The respondents were highly satisfied with meeting expectations to attain objectives, training and workshop contents, learning activities, methodologies, instructional materials used, resource person and trainers, training management team, and training management team and training facilities and services. Further, there was no significant difference among their level of satisfaction from day 1 to 5 of the training sessions. Respondents viewed the training as very successful, as evident from the consultation and culminating activity. Thus, the sustainability on the implementation of the project was highly recommended.
\end{abstract}

Keywords:

robotics education, roboteach extension project, $\mathrm{K}$ to 12 education, teacher training and development, curriculum enhancement

Suggested Citation: Gonzales, M.C., Andal, E.Z., Ching, D.A., Gaffud, M.P. \& Tabo, E.C. (2021). Assessing the Efficacy of RoboTeach Extension Project on Public School Teachers. International Journal of Educational Management and Development Studies, Volume 2, Issue 3, pp. $78-100$.

\footnotetext{
About the authors:

${ }^{1}$ Corresponding author. Instructor 1, Laguna State Polytechnic University- San Pablo City Campus

${ }^{2}$ Associate Professor 5, Laguna State Polytechnic University-San Pablo City Campus

${ }^{3}$ Instructor 1, Laguna State Polytechnic University-San Pablo City Campus
} 


\section{Introduction}

In most industrialized countries, educational robotics programs have become increasingly popular wherein robots were utilized as a tool for teaching pupils at various levels of education to motivate students to explore science, technology, engineering, and mathematics (Miller et al., 2016). Robotics was considered as one of the most modern instructional tool (Lopez-Belonte et al., 2021) and its integration in early learning classrooms has been found to provide value to educational processes (Papadakis et al., 2021). Robotics is the application of technology, computer, mathematics, and science to increase productivity, improves skills in problem solving, working, collaborative learning and provides awareness to technology and it is important in addressing the country's current and future challenges (He, et al., 2019; Montemayor, 2018; Gokcearslan et al., 2018). Interaction with robots boosts motivation, engagement, and attitude toward education (Kaloti-Hallak, 2014). The simplicity of the robot design and assembly process, the inclusion of simple visual drag-anddrop programming, and the progressively decreasing cost of educational robot platforms marked the beginning of a new age in educational technology. However, future progress would need the identification of possible constraints and the subsequent reasonable adaptation (Kari, et al., 2015).

Technology is not being used to replace teachers; rather, it is being used to aid teachers and students in creating a suitable methodologically diversified learning environment (Sabine et al., 2014; DeCoito, et al., 2018; He, et al., 2019; Newton \& Newton, 2019). Teachers are one of the most important components in the educational system and they must feel at ease with robots and such comfort can only be attained via good training and active/pro-active participation. However, many teachers are hesitant to deal with robotics not because of lack of desire to learn new ideas but due to a lack of conventional curriculum and the accompanying long-term benefits (Sabine et al., 2014; Usman, 2016). These constraints can be reduced by effective training, adoption of appropriate technology, creating uniform, consistent long-term curriculum (Alimisis, 2013) and both individual and collaborative learning should be expressly encouraged in the educational system (Karim, 2015; He, et al., 2019; U.S. Department of Education, 2017; Gokcearslan et al., 2018). 
According to De La Salle Santiago Zobel School International Robotics Coordinator, Genevieve Pillar (2018), robotics is one of the needs of the 21 st century learners that must be integrated in schools and be taught and carried out within the curriculum in classrooms because if not, the students will be left behind by other countries. Moreover, the DepEd Undersecretary Anne Sevilla (2018) stated that the study of robotics should be encouraged among all students because it is beneficial to human quality of life. However, robotics was only an elective subject taught in special class (Benitti, 2011), science high schools and just part of the science investigatory projects whereas they can easily adjust and incorporate robotics subjects in class (Montemayor, 2018).

Robotics can provide opportunities to fulfil DepEd's noble aim of improving its existing $\mathrm{K}$ to 12 curriculum through diverse methods of learning as necessary for education in the 21st century (Agapito, 2021). In the light of the campaign of the DepEd to employ robotics in education, the Laguna State Polytechnic University (LSPU) and, Ideation Design and Development Laboratory (IDD Lab) in collaboration with the Department of Science and Technology (DOST) CALABARZON, had conceptualized the RoboTeach Project which aimed to equip educators towards industry 4.0. LSPU extensionists and researchers have conducted assessment on the level of knowledge on 25 selected teachers from public schools in DepEd Division of San Pablo City, Laguna, Philippines to determine the needs and challenges on the implementation of robotics in K-12 education. Based from the results of the assessment, one of the identified challenges was the educational incapacity of the teachers to teach robotics because most of them do not have skills and knowledge on the basic electronics and robotics concepts. Second, was the high cost of materials, thus only those students in the private schools were able to join robotics competition since the robots and materials used were relatively expensive. Another challenge was the inadequate machinery used in the production and assembly of modules and kits. Lastly, is the lack of technical assistance from experts (Gonzales et al., 2020). Those challenges served as the foundation for the establishment of a training plan that fulfilled the needs of the department in the promotion and implementation of the project.

The RoboTeach Project was composed of ten days training-workshop, consultation and culminating activity. It was institutionally and externally funded research and extension initiative of the College of Industrial Technology (CIT) and College of Teacher Education 
(CTE) of LSPU. The topics and learning activities covered by the ten-day training were based on the self-assessment survey results on the level of knowledge of teachers which was conducted prior the actual implementation of the project. According to the evaluation results, most of the teachers had no specific knowledge with the fundamental and digital electronics, microcontrollers, microelectronics and programming which were the foundations in robotics education. The results emphasized that training is necessary in order to employ robotics in their class (Gonzales, et al., 2020).

The theoretical aspect of the training was conducted thru online conferencing due to the restrictions brought about by the COVID-19 pandemic. While, actual demonstration and hands-on activities were undertaken face-to-face, rest assured that the participants, trainers and facilitators strictly followed the necessary health and safety protocols. The RoboTeach Module First Edition was developed as part of the deliverables of the project. It was tested and validated by experts to ensure meeting the objectives and expectations of the clientele. After the training, consultation and mentoring were implemented to assist the teachers in designing, programming, product development and robot assembly. As part of the culminating activity, Robotics Olympics was launched to showcase the skills and outputs of the participants. PBOT2018 mobile robot was utilized by the participants during the Olympics (Gonzales, et al., 2020). It is a mobile robot kit that operates as a line tracing, collision avoidance, maze and sumo battle developed by e-Gizmo intended for students, hobbyists and researchers who would like to learn basic programming in Arduino (PBOT 2018 Entry Level Mobile Robot Controller - Introduction, 2018).

In order to analyze the quality of the project implementation and clientele's feedback, impact assessment must be carried out (Pentang, 2021). Thus, the general objective of this study was to determine the perception of the teachers on the efficacy of the implementation of the RoboTeach Extension Project. The study specifically aimed to determine the perceived level of satisfaction of the respondents on the 5-day training. It also seek to determine if there was a significant difference among the level of satisfaction from Day 1 to 5 of the respondents and assess the level of success of the RoboTeach Project in achieving its goal for the teachers to learn basic programming and robotics based on conducted consultation and culminating activity. 


\section{Literature review}

\subsection{Benefits of Robots in Education}

Robotic technological advancements has introduced new educational activities, with the most of its applications focused on teaching courses such as robot programming, robot construction, or mechatronics (Mitnik et al., 2008). Many people believed that robots provide an invaluable source of motivation for students to learn. However, it is important to recognize exactly what the robot has to contribute to learning (Benitti, 2016).

Robots can serve as a programming project, a learning focus, or a learning collaborator in an educational context (Miller et al., 2016). It also offers the opportunity to transform traditional education into a unique form of innovative learning process (Alimisis, 2013). Educational robotics offers a practical approach to learning and provides a fun and exciting environment that enhances the learning experiences of students, provides many opportunities to integrate across many disciplines while at the same time enabling students to work together to encourage cooperation, communicate by utilizing technology tools, solve problems, and think critically and innovatively (Eguchi, 2017). All students can benefit from robotics and it can be a tool (Frangou, et al., 2008) for fostering cognitive, personal growth, and teamwork, allowing students to enhance their performance and utilize their creativity, communicate ideas, and encourage effective and valuable decisions in life (Alimisis, 2013; Gokcearslan et al., 2018; Chang \& Chen, 2018).

Teachers must be educated on the benefits that robots may provide them (Negrini, 2018). Robotics contributes to teachers' professional development primarily in the areas of keeping abreast with evolving technology and practices, which benefits their students and increases productivity. According to the instructors of IT in Turkey (2018), robots provide a major effect on their professional growth. It updates them on the new technologies and developments, which help the growth of student abilities and productivity. Robots were also proven entertaining, engaging and a great tool for student creativity, critical thinking, troubleshooting and collaboration development (Gokcearslan et al., 2018).

Science, Technology, Engineering and Mathematics (STEM) may be taught more effectively by incorporating robotics as it enables real-world applications of engineering and technology principles (Nall, 2016), significantly reduces science and mathematics complexity 
and enhances STEM learning and performance skills (Kim et al., 2015; Chang \& Chen, 2018). The Robotic program made a significant contribution to students' competence and skills in the field of technology, revolutionized schools and fulfilled education requirements in the 21 st century through the integration of Robots into the curriculum (Agapito, 2021).

\subsection{Challenges on the Integration of Robotics in the Curriculum}

Despite the fact that technology may be found everywhere, it is not prevalent in classrooms (OECD, 2018) specifically in public education which has not kept paced with the rapid changing technology (Eguchi, 2017). The widespread utilization of instructional robots has several problems and constraints. Some of the drawbacks on the implementation of a robotics program in school includes the high initial expenditures, the cost of sustaining a robotics program and instructors' willingness to learn and use various areas of computer technology and science, the lack of proper teacher training, complex methodologies and the difficulty of robots to depict emotions appropriately (Gorakhnath \& Padmanabhan, 2017; Flores, 2006).

Most schools oppose incorporating robotics into the curriculum due to time constraints and the high cost of materials and equipment (Mouhamad, 2019). Most public schools relatively have a huge number of students and teachers also lacked skills and training on robotics and the cost of kits were also too expensive for public schools, which were the major challenges to adopt the technology. Thus, sufficient funds must be provided to include robotics into their curriculum (Gokcearslan et al., 2018; Coskunserce, 2021).

The integration of robot into class provides the students the skills of critical thinking, problem solving, teamwork, and engineering (Chang \& Chen, 2018). However, instructors may employ new technologies less easily without proof that teaching and student learning can be supported. In order to successfully integrate robotics in class, instructors may need to lead, or at least contribute to the unit design in order to fulfil instructional goals and classroom requirements and, the design and learning assessments must be guided by disciplinary standard and goals. Moreover, instructors who have never worked with robots or developed curriculum, robotics integration projects can be challenging (Bernstein et al., 2020). 
Most teachers are unfamiliar with the benefits of educational robotics (Alimisis et al., 2007). Teachers are usually unprepared to use robots in the classroom (Mataric et al., 2007) and find it very difficult to integrate robots in their regular curriculum because the emphasis is heavily on meeting the institution's assessment standard and academic requirements (Eguchi, 2017). One of the most significant barriers early childhood educators have when attempting to implement new technology curricula and for effectively executing a robotics program is a lack of understanding of how the technology components function and, the teacher's familiarity and confidence with robotics materials (Bers, 2008).

One of the most significant challenges in robotics education is the development of a standardized curriculum that can be transferred into other disciplines (Chang \& Chen, 2018; Alimisis, 2013; Benitti, 2012). The benefit of having a curriculum is that it creates a standard asset, serves as a resource, identifies the student's learning, reduces the workload and eliminates redundancy in designing an essential robotics program that allows for quick application in an educational environment (Berry et al., 2016). A standard robotics curriculum can accommodate all levels of student competence and compensate for the diverse range of experiences that students in a specific classroom or outreach activity may have. One aspect of hesitance in adopting robots might be stakeholders' unwillingness to articulate, confirm, and convey whether or not the learning efforts create a transferable skill or what pupils are learning (Berry et al., 2016). A systematic robotic integration strategy in education is therefore needed to provide a coherent assessment and evaluation in a wide range of learning settings, allowing best practice and leading discussions on robotics as a learning resource (Jomento-Cruz \& Lorelei, 2010).

The curriculum should be flexible, simple, and suited for different robotics and learning platforms. It should also give a broad set of skills based on these ideas, without concentrating on the specific hardware or software platform to encourage a range of skills for the use of robotic concepts, to educate or strengthen co-curricular concepts and to offer momentary solutions. Thus, modifications to training and availability of alternative robotic kits for sustainable robotic education is essential (Agapito, 2021; Berry et al., 2016). Robotics promotes teamwork and collaboration. However, the individual differences and diversity of the students also provides a great impact on the efficacy of the robotic program, because some students do not want to participate and collaborate with others (Flores, 2006). 


\subsection{Reviews on Educational Robotics}

Educational robotics provides potential to be a supplementary aid and learning tool to traditional education and its tangibility, as well as the interest they bring to the classroom setting, was seen to be beneficial to learning (Ntemngwa \& Oliver, 2018). Empirical studies have encouraged several schools to include robotics into their formal or informal curricula. However, the major role of robots to STEM education is unclear thus the observation on several factors to enhance success in further research was recommended (Datteri, et al., 2013). A review conducted by Benitti, (2012), investigated the efficacy of educational robotics, concentrating on studies using robots in school classrooms but excluding those conducted in informal settings. Because formal and informal teaching and learning techniques vary, a systematic study employing a rigorous methodology is required to properly understand how educational robots influences children's academic, motivational, and social abilities. The review also provided a solid foundation for the current analysis; however, it had several limitations, including a limited number of studies, the use of only quantitative evaluation of learning, and the failure to account for the underlying theoretical foundations that made specific forms of robot-based pedagogy more efficient.

Karim et al. (2015) conducted a review on reshaping K-12 STEM Education, which underlined the significance of educational modules. However, due to the small number of studies included, the study failed to highlight the most successful robotic pedagogy and theoretical frameworks foundations needed for instructional modules in STEM education is important. It also found many limitations in robotics platforms and instructional settings and proposed an educational framework for combining robotics with augmented reality. The study have identified two critical issues to supplement traditional K-12 curricula and associated teacher training programs which included the standardization of evaluation techniques used to quantify robot-based learning, the integration of statistical analysis, surveys, and interviews, and the development of customized robot-based pedagogical modules.

The pedagogical tool in K-12 STEM education has become significant for educational robots (Coskunserce, 2021). The number of studies on educational robots and their influence on academic and social abilities of young students has dramatically increased however; a systemic assessment on the efficiency of educational robots in both formal and 
informal settings is needed to fully integrate robotics in the education. With such a high level of interest in educational robots, it is important to investigate these efforts in order to understand how robotics has been used as an innovative tool, as well as to conduct comparative studies that investigate the relative effectiveness of educational robots in comparison to other approaches. The literature review conducted by Anwar et al. (2019) captures how and in what subjects did teachers and researchers have attempted to use educational robotics, and also highlighted the complex psychological, organizational, and cultural mechanisms that influence robotics' capacity to improve students' motivation and learning outcomes. Based on the systematic review conducted, it was evident that educational robotics took place at various levels and with varying scopes. Educational robots have the potential to be utilized as learning and teaching tool, including aid in the education of students who have no prior interest in academic areas linked to science or technology (Scaradozzi et al., 2015). Educational robotics also enables a multidisciplinary, integrative approach that includes technical and social themes that helps students to form mental associations and linkages with a wide range of engineering, physics, and mechanical ideas (Coskunserce, 2021). To engage kids and enhance the learning process, researchers and $\mathrm{K}-12$ instructors must use a variety of cognitive and emotional techniques in conjunction with robotic platforms (Anwar et al., 2019).

The study of William et al. (2007) revealed that students were less interested in traditional classes and more likely to participate in robotics assembly and programming activities. Lessons, tutorials, and examples should be integrated into robotics programs to encourage scientific inquiry and content knowledge development. The first principle was to promote scientific inquiry and content knowledge acquisition, just-in-time resources such as lessons, tutorials, and examples should be incorporated in robotics applications. Second, students should also be encouraged to explain their design by mentioning related scientific concepts and principles. A robotics curriculum should allow students to explore the learning environment while also encouraging them to use the scientific inquiry method to accomplish design problems and maximize their strengths (The Five Unexpected Benefits of Robotics in the Classroom, 2016). Students with varying degrees of topic understanding and problemsolving abilities may require alternative exercises in robotics programs. Lastly, robotics 
program should equip facilitators with the knowledge and abilities necessary to promote scientific inquiry (Ntemngwa, 2018).

\subsection{Methods and Approaches in Teaching Robotics}

The main theories behind educational robotics are constructivism and constructionism whereas the educator's role is to offer opportunities for children to engage in hands-on explorations and to provide tools for knowledge construction (Alimisis, 2014).

Robotics is a growing research topic, and in the educational process, the usage of robot components has emerged as an innovative and successful learning aid (Conkunserce, 2021). A broader set of skills, and the use of robots as an alternative tool for teaching and learning topics has been established. Specific teaching strategies and tools suited for incorporating educational robots into the process must be established (Ntemngwa, 2018) and integrated to the general curriculum. Problem/inquiry-based learning, project-based learning, and competition-based learning are some of the most suitable learning approaches that can be used in teaching robotics (Eguchi, et al., 2010; Kubilinskiene et al., 2017; Alimisis, 2013). Teachers generally prefer demonstration, hands-on practice and performance approach (Gokcearslan, et al., 2018; Ntemngwa, 2018).

\subsection{Effectiveness of Robotics in Education}

A significant standard of technological stability and standardization is necessary to make educational robots effective (Miller et al., 2016). Educational robotics heavily relies on curriculum, which must include fundamental learning concepts and provide qualitative and quantitative performance indicators for desired results, as well as be validated by the curriculum itself (Alimisis, 2013). The effectiveness of the integration of robotics in classroom can also be obtained when technology and resources were properly utilized and integrated with the students' educational requirements (Thomaz et al., 2009). Several ranges of factors must also be addressed to satisfy the expectations of both teacher and learner in order to employ robots effectively in education (Gereke et al., 2007). The usability and the availability of appropriate learning activities and material are also significant variables that effect the effectiveness of robots to learning (Gorakhnath \& Padmanabhan, 2017). 
It is necessary for a robotics program to require final assessment or project to provide simpler and effective measurement, enhanced the reliability of the study, and improve the accuracy of the results. It would ensure that learners received the necessary skills and that the effectiveness of the program or other variables was effectively measured (Schina et al., 2020). It also encourages participants to address the non-ideality of real-world devices rather than relying on a simulation, and gives immediate feedback on the success or failure of their ideas (Goh \& Baharuddin, 2007). Students' cognitive abilities were improved and their motivation to be active learners was stimulated by project-based courses that challenge their creativity (Sánchez et al., 2019; Alimisis, 2013).

Conducting longitudinal and validated research studies (Alimisis, 2013), strengthening the descriptions of the training programs with details on the total number of training hours, attendance hours, teaching practice hours, and increasing the duration of the training programs, and increasing the duration of the training programs improves the reliability of the study on the effectiveness of robotics in education (Schina et al., 2020).

Teachers should test robotic curriculum before implementing them in their classrooms and the different strategies to introduce robotics technology and concepts must be employed (Alimisis, 2013). Teachers act as facilitators and enablers in educational robotics contexts, organize the learning environment, assign tasks/problems to be addressed, and provide the tools and assistance needed to encourage students' participation (Ntemngwa, 2018). The instructor also provides assistance to students and encourages them to try out new ideas and solutions, fosters cooperation, and establishes activity assessments in collaboration with the students (Alimisis, 2019). The study of Bernstein et al. (2020), had revealed three key elements that influenced the integration of robotics in the curriculum which includes motivation, design decision and approaches to sustain the implementation of robotics.

Public education did not keep paced with the fast changing technology. Several education innovation, such as education robots, manufacturers' movement and digital production, can bring about improvements in formal education that should be brought into regular educational classrooms and, must be made accessible to all students (Montemayor, 2018). Creating of robots offers integrated learning environments in which students may meet a variety of STEM concepts and ideas from other areas of study in contextual manner. The use of robots can create a non-traditional educational setting that stimulates the curiosity, 
learning excitement, inventiveness and self-confidence of students (Eguchi, 2017). STEM education may be increased by developing an efficient, industry-oriented training program on educational robots and the efficacy of the implementation of robotics in education depends on the learners capability to adopt, sustain, maintain, enhance and transfer the technology (Sergeyev et al., 2016).

\subsection{Components of Robotics Education}

Better training leads to greater benefits (Leeuw, 2009). Teachers must be trained first with robotics to make them competent, skilled and confident to teach their students (Negrini, 2018). Teachers who undertake professional development are more inclined to interact with others through a wider range of teaching techniques (Tallis, 2009). Training is a critical component in achieving goals and is likely to accomplish its objectives and increase productivity. It is an important approach to retain competent teachers. Therefore, training and re-training of teachers is necessary to achieve the goals (Iyewa \& Gberevbie, 2017) of employing robotics in the curriculum.

A robot is not sufficient to develop skills in the classroom. Teachers need materials, appropriate models, instructional methods and didactic exercises that are essential aspect in the introduction of robotics into classrooms (Negrini, 2018).

The proper educational philosophy, curriculum, and learning environment are some of

the key components that may contribute to the success of robotics in education. The curriculum influences learning outcomes and technological alignment with successful learning theories. It also serves as the foundation of educational robotics, and it is essential to include basic learning concepts as well as to provide qualitative and quantitative performance indicators for expected outcomes and curriculum validation (Alimisis, 2013).

\subsection{Impact Assessment and Feedback}

Impact assessment plays a significant role in achieving better outcomes and identifies important issues on training efficacy, adaptability and cost-effectiveness. It also allocates resources where the most developmental effects may be achieved (Leeuw, 2009).

Success must be defined and rubrics must be utilized before conducting evaluation to determine levels of performance detail the evidence obtained and summarize acceptable 
conclusions on the effectiveness of the program. Moreover, lack of systematic approach of assessment has high risk of obtaining incorrect information and inaccurate judgments (Peersman, 2015).

Feedback systems have a significant positive relationship with training efficiency as they help to identify the gaps between the trainees' present and future skill requirements. Feedback may also provide information on the correctness, timeliness, appropriateness and, accuracy of the training objectives (Oludeyi, 2018).

\section{Methodology}

The study used descriptive research design. It is descriptive in nature as it aimed to recognize the impact of the implementation of the project and the LSPU Extension Services Evaluation Survey Questionnaire was utilized to assess the efficacy of the project. In assessing the implementation of the project, the extension evaluation tool was used using the parameters on meeting the expectations, attainment of the objectives, training/ workshop content, activities included, methodologies, instructional/ presentation aids, choice of resource persons/ panellists, training management team and training facilities and services.

The respondents of the study were composed of 25 teachers from different public schools in one city in the Philippines. Most of the participants who attended the 5-day training on RoboTeach Project were dominated by males whose civil status is single. Males were more inclined to believe that robot have or will have their own desires, preferences, intentions and future goals than females (Briggs \& Scheutz, 2014). The participants were selected by the key officials and coordinators of DepEd and those teachers who participated in the project were mostly designated as teacher I who were still on progress and in their early moments of teaching students supported by the data that most of them are 1-5 years in the service. It implies that the division have selected younger teachers that they believe were more familiar on computers and modern technology and they are the one's who are eager to learn new concepts and are interested in learning robotics. They were also currently taking their master's degree which posted their interest to grow professionally and by taking into account their participation to RoboTeach will contribute as well to their motive. The teacherparticipants of the training were mostly professionals who passed the Licensure Examination for Teachers and only some has attended at least one training related to robotics. These baseline information from the teachers serve as bases for the extensionist in the CIT and 
CTE to conduct RoboTeach Training for DepEd teachers.

The data were analyzed using descriptive statistics such as frequency count, per cent, weighted mean and standard deviation to determine the level of efficacy of the project. In finding out if, there is a significant difference among their level of satisfaction from day 1 to 5 of the training sessions; the Analysis of Variance (ANOVA) was used.

The research procedure comprised five stages. The first stage focused on the assessment of the skills and needs of the participants that became the basis for the implementation of the project. Second, is the actual implementation composed of a 5 days training and 5 days product development and consultation. To determine the efficacy of the project, culminating activity was conducted after the training and the actual output of the participants were showcased thru Robotics Olympics. Lastly, an evaluation was conducted to determine the level of satisfaction and efficacy of the training as perceived by the teachers.

\section{Findings and Discussion}

\section{Table 1}

Level of Satisfaction on the 5-Day Training

\begin{tabular}{|c|c|c|c|c|c|c|c|c|c|c|}
\hline \multirow{2}{*}{ Satisfaction Criteria } & \multicolumn{2}{|c|}{ Day 1} & \multicolumn{2}{|c|}{ Day 2} & \multicolumn{2}{|c|}{ Day 3} & \multicolumn{2}{|c|}{ Day 4} & \multicolumn{2}{|c|}{ Day 5} \\
\hline & Mean & SD & Mean & SD & Mean & SD & Mean & SD & Mean & SD \\
\hline Meeting the Expectations & $3.75^{\mathrm{a}}$ & 0.44 & $3.88^{\mathrm{a}}$ & 0.34 & $4.00^{\mathrm{a}}$ & 0.00 & $4.00^{\mathrm{a}}$ & 0.00 & $3.96^{\mathrm{a}}$ & 0.20 \\
\hline Attainment of Objectives & $3.79^{\mathrm{a}}$ & 0.41 & $3.83^{\mathrm{a}}$ & 0.38 & $4.00^{\mathrm{a}}$ & 0.00 & $4.00^{\mathrm{a}}$ & 0.00 & $4.00^{\mathrm{a}}$ & 0.00 \\
\hline Training/ Workshop contents & $3.88^{\mathrm{a}}$ & 0.34 & $3.83^{\mathrm{a}}$ & 0.38 & $4.00^{\mathrm{a}}$ & 0.00 & $4.00^{\mathrm{a}}$ & 0.00 & $3.96^{\mathrm{a}}$ & 0.20 \\
\hline Activities Included & $3.83^{\mathrm{a}}$ & 0.38 & $3.88^{\mathrm{a}}$ & 0.34 & $4.00^{\mathrm{a}}$ & 0.00 & $4.00^{\mathrm{a}}$ & 0.00 & $3.92^{\mathrm{a}}$ & 0.28 \\
\hline Methodologies & $3.75^{\mathrm{a}}$ & 0.44 & $3.83^{\mathrm{a}}$ & 0.38 & $4.00^{\mathrm{a}}$ & 0.00 & $4.00^{\mathrm{a}}$ & 0.00 & $3.92^{\mathrm{a}}$ & 0.28 \\
\hline Instructional/ Presentation Aids & $3.92^{\mathrm{a}}$ & 0.28 & $3.96^{\mathrm{a}}$ & 0.20 & $3.96^{\mathrm{a}}$ & 0.20 & $4.00^{\mathrm{a}}$ & 0.00 & $3.96^{\mathrm{a}}$ & 0.20 \\
\hline $\begin{array}{l}\text { Choice of Resource Persons/ } \\
\text { Panelists }\end{array}$ & $3.88^{\mathrm{a}}$ & 0.34 & $3.83^{\mathrm{a}}$ & 0.38 & $4.00^{\mathrm{a}}$ & 0.00 & $4.00^{\mathrm{a}}$ & 0.00 & $4.00^{\mathrm{a}}$ & 0.00 \\
\hline Training Management Team & $3.79^{\mathrm{a}}$ & 0.41 & $3.92^{\mathrm{a}}$ & 0.28 & $4.00^{\mathrm{a}}$ & 0.00 & $4.00^{\mathrm{a}}$ & 0.00 & $3.96^{\mathrm{a}}$ & 0.20 \\
\hline Training Facilities and Services & $3.83^{\mathrm{a}}$ & 0.38 & $3.92^{\mathrm{a}}$ & 0.28 & $4.00^{\mathrm{a}}$ & 0.00 & $4.00^{\mathrm{a}}$ & 0.00 & $4.00^{\mathrm{a}}$ & 0.00 \\
\hline Overall & $3.82^{a}$ & $\mathbf{0 . 3 3}$ & $3.88^{a}$ & 0.28 & $4.00^{a}$ & 0.02 & $4.00^{a}$ & 0.00 & $3.96^{\mathrm{a}}$ & 0.11 \\
\hline
\end{tabular}

Legend: (a) 3.50-4.00 Very Satisfied; (b) 2.50-3.49 Satisfied; (c) 1.50-2.49 Somewhat Satisfied; (d) 1.00-1.49 Not Satisfied

As revealed in the conducted evaluation of the project (Table 1) which renders training service to the DepEd teachers, participants are very satisfied from Day 1 to 5 that the project met the expected outcomes of the RoboTeach Project. The training session provided 
actual demonstration and hands-on practice on basic programming, hardware interfacing and, product assembly which were effectively met by the training. Achieving these expected deliverables would help them apply and further explore the concept in a broader perspective (Javed, Muneer \& Anuar, 2013).

The participants are very satisfied that the objectives set in the training were attained from Day 1-5. The performance and outputs of the participants during the culminating activity in the Robotics Olympics showed that they have learned the theories and concepts of electronics, fundamentals of microcontroller, programming, product assembly and test. The training objectives that are carefully planned would lead to a sustainable implementation of the project being imposed (Iyewa \& Gberevbie, 2017).

In addition, the participants are very satisfied to the delivered contents during the training. There were 5 mentors who have shared their knowledge and skills to participants with regards to programming, designing and assembling of robots. The content delivered in the training that is closely connected to the rationale of the activity capacitates the participants to master the expected competency about robotics (Ospennikova, et al., 2015; Agatolio, et al., 2016).

The activities that are initiated in the training program were rated with very satisfactory level. This means that the organized activities, where the required skills are well applied are acknowledged to be helpful among them. Participants performed manual soldering, resistor color coding, testing and circuit assembly which is the foundation for them to build their robot. Having hands-on activities in certain robotics training helped participants to realize its effectiveness and applicative meaning (Ziaeefard, et al. 2017; Kaloti-Hallak, 2014).

Similarly, the methodologies used by the facilitators in the conduct of the training were found to be very satisfactory. From the start of the program until the end, the facilitators well planned every single action they have to work on. Despite the current situation of community quarantine, the program was initiated effectively through online platforms. It is manifested that when the generalized methodology used in a particular robotics training it enables a more structured process in learning the required goal of the activity for potential better results (Nurbekova, et al., 2018; Du, Wang, Li, 2020). 
It is revealed also in the table that the instructional resources and presentations used by the trainers are very satisfactory. It upholds clear discussion with minimal animation and designs which appeals the most the teacher-participants since they are already professionals. The experts proofread and reviewed the PowerPoint presentation used in the training to ensure that the contents were clear, simple and relevant to the learning objectives specified in the training plan. Presentations with minimal distractions to the viewers are more interesting to be shown and can be easily understood and considerably more professional (Jones, 2003; Shehata \& Strömbäck, 2013). The teachers also appreciated the provided RoboTeach Module that they have used as guide during their training journey. Teachers need materials, appropriate models, instructional methods and didactic exercises that are essential aspect in the introduction of robotics into classrooms (Negrini, 2018).

Furthermore, the choice of resource persons/panellists in the training is very satisfactory. This means that the selection of the dean of the college and the extension project head is truly commendable. The trainers chosen to deliver are experts in their chosen field who are credible to deliver the topics covered in the training. The success of the training lies on how the resource persons well shared the contents if the training who are knowledgeable, skilled and experts of the topic held to them (Wisshak \& Hochholdinger, 2018; CEDEFOP \& European Commission, 2016).

It is reflected in table 2 that there is no significant difference among the level of satisfaction of the respondents from Day 1 to 5 . The computed p-values that are greater than 0.05 level of significance include meeting the expectations $(\mathrm{p}=0.139)$, attainment of the objectives $(p=0.954)$, training/ workshop content $(p=0.064)$, activities included $(p=0.104)$, methodologies $(\mathrm{p}=0.104)$, instructional/ presentation aids $(\mathrm{p}=0.729)$, choice of resource persons/ panellists $(\mathrm{p}=0.086)$, training management team $(\mathrm{p}=0.392)$ and training facilities and services $(\mathrm{p}=.086)$. This implies that there is a consistent level of satisfaction from day 1 to 5 from each of the constructs of assessments. It is evident that the activity was found very satisfactory and it has achieved the deliverables in every session. The training facilitated by the CIT on RoboTeach is effective and is commendable to be sustained. 
International Journal of Educational Management and Development Studies, Volume 2 Issue 3

Table 2

Test of Significant Difference among the Level of Satisfaction from Day 1 to 5

\begin{tabular}{|c|c|c|c|c|c|c|}
\hline \multicolumn{2}{|c|}{ ANOVA Analysis } & \multirow{2}{*}{$\begin{array}{c}\begin{array}{c}\text { Sum of } \\
\text { Squares }\end{array} \\
.383\end{array}$} & \multirow{2}{*}{$\begin{array}{c}\text { df } \\
4\end{array}$} & \multirow{2}{*}{$\begin{array}{c}\begin{array}{c}\text { Mean } \\
\text { Square }\end{array} \\
.096\end{array}$} & \multirow{2}{*}{$\begin{array}{c}\mathbf{F} \\
1.775\end{array}$} & \multirow{2}{*}{$\begin{array}{l}\text { Sig. } \\
.139\end{array}$} \\
\hline Meeting the Expectations & Between Groups & & & & & \\
\hline & Within Groups & 6.208 & 115 & .054 & & \\
\hline & Total & 6.592 & 119 & & & \\
\hline \multirow[t]{3}{*}{ Attainment of the Objectives } & Between Groups & .033 & 4 & .008 & .169 & .954 \\
\hline & Within Groups & 5.667 & 115 & .049 & & \\
\hline & Total & 5.700 & 119 & & & \\
\hline \multirow[t]{3}{*}{ Training/ Workshop Content } & Between Groups & .550 & 4 & .138 & 2.286 & .064 \\
\hline & Within Groups & 6.917 & 115 & .060 & & \\
\hline & Total & 7.467 & 119 & & & \\
\hline \multirow[t]{3}{*}{ Activities Included } & Between Groups & .533 & 4 & .133 & 1.968 & .104 \\
\hline & Within Groups & 7.792 & 115 & .068 & & \\
\hline & Total & 8.325 & 119 & & & \\
\hline \multirow[t]{3}{*}{ Methodologies } & Between Groups & .533 & 4 & .133 & 1.968 & .104 \\
\hline & Within Groups & 7.792 & 115 & .068 & & \\
\hline & Total & 8.325 & 119 & & & \\
\hline \multirow[t]{3}{*}{ Instructional/ Presentation Aids } & Between Groups & .083 & 4 & .021 & .509 & .729 \\
\hline & Within Groups & 4.708 & 115 & .041 & & \\
\hline & Total & 4.792 & 119 & & & \\
\hline \multirow{3}{*}{$\begin{array}{l}\text { Choice of Resource Persons/ } \\
\text { Panelists }\end{array}$} & Between Groups & .133 & 4 & .033 & 2.091 & .086 \\
\hline & Within Groups & 1.833 & 115 & .016 & & \\
\hline & Total & 1.967 & 119 & & & \\
\hline \multirow[t]{3}{*}{ Training Management Team } & Between Groups & .167 & 4 & .042 & 1.036 & .392 \\
\hline & Within Groups & 4.625 & 115 & .040 & & \\
\hline & Total & 4.792 & 119 & & & \\
\hline \multirow[t]{3}{*}{ Training Facilities and Services } & Between Groups & .133 & 4 & .033 & 2.091 & .086 \\
\hline & Within Groups & 1.833 & 115 & .016 & & \\
\hline & Total & 1.967 & 119 & & & \\
\hline
\end{tabular}

The success of the training lies on a well-planned action of the facilitators. If all potential needs of the training are satisfied through a well-noted plan considering several aspects like trainers, activities to be administered, methodologies to execute, management parameters and others, it likely contributes to attain success of the training program (DarlingHammond, Hyler \& Gardner, 2017). If all the teacher-participants are involved and engaged well in the training, such that participants were given time to engage in the style or manner of training delivery, given interactive presentations and a more contextualized robotics applications, it would help the facilitators realize more the success of the training program (Papadakis, et al., 2021). 
Table 3

Level of Success of the RoboTeach Project

\begin{tabular}{|c|c|c|c|}
\hline Indicators & Mean & SD & Interpretation \\
\hline Consultation & 3.95 & 0.12 & Very Successful \\
\hline Culminating Activity & 3.99 & 0.07 & Very Successful \\
\hline Overall & 3.97 & 0.10 & Very Successful \\
\hline
\end{tabular}

The results of the evaluation as gleaned from table 3 revealed that the consultation conducted during the implementation of RoboTeach Project was very successful. The participants' inquiries were addressed, and the trainers' advice assisted the participants in optimizing their productivity. Whenever students have challenges in developing and executing problems, instructor needs to provide support to enable the student to accomplish the project tasks (Flores, 2006) and the success of a training process is determined by the relationship between the teacher and the learner (Assadi et al., 2019).

It can also be observed from the table above that the culminating activity was very successful. One of the highlights of the project was the Robotics Olympics whereas the participants exhibited their skills in programming, design and assembly of robots. The participant acquired and applied what they have learned during the training as manifested by their performance and skills demonstrated during the activity. A final project or requirement provides simpler and effective measurement, enhances the reliability of the study and improves the accuracy of the results (Schina et al., 2020).

\section{Conclusion}

The RoboTeach Extension Project trained the teachers on robotics education through training session, demonstration and hands-on activities that include the basic theories and concepts of electronics, software and hardware interfacing, programming, designing and robot assembly. The study examined the effect of the project's implementation using feedback obtained from the clientele served in order to determine the extent of its implementation. The training demonstrated the competence and creativity of the participants. As a result, the project met the expectations of the clientele and viewed that the overall implementation of the project very successful. There was also no significant difference found 
among the level of satisfaction with the project's implementation. The study has manifested that the project was carried out effectively. Thus, it is recommended that the project be sustained and the robotics be integrated in the education. It is also highly recommended to target more participants of the study by identifying those secondary teachers who are engage in technology related subjects since it was depicted that it is limited to 25 key officials and coordinators chosen to represent the school.

\section{Acknowledgement}

This project was funded by the Laguna State Polytechnic University and Department of

Science and Technology, CALABARZON Region IV-A.

\section{References}

Agapito, L.G. (2021). Exploring the Exploits on the Instructional Conveyance of Robotics Course to the 4Cs of 21st Century Education. International Journal of Information and Communication Technology and Education, Volume 2, Issue 1, pp. 1- 18.

Agatolio, F., Pivetti, M., Di Battista, S., Menegatti, E., \& Moro, M. (2016, November). A training course in educational robotics for learning support teachers. In International Conference EduRobotics 2016 (pp. 43-57). Springer, Cham.

Alimisis, Dimitris. (2013). Educational robotics: Open questions and new challenges. Themes in Science \& Technology Education,. Published. https://files.eric.ed.gov/fulltext/EJ1130924.pdf

Alimisis, D. (2014). Chapter Two Educational Robotics in Teacher Education: An Innovative Tool for Promoting Quality Education. The Teacher of the 21st Century: Quality Education for Quality Teaching, 14.

Alimisis, D. (2018). Teacher training in educational robotics: The ROBOESL project paradigm. Technology, Knowledge and Learning, 24(2), 279 290. https://doi.org/10.1007/s10758-018-9357-0.

Anwar, S., Bascou, N. A., Menekse, M., \& Kardgar, A. (2019). A Systematic Review of Studies on Educational Robotics. Journal of Pre-College Engineering Education Research (J-PEER), 9(2), Article 2. https://doi.org/10.7771/2157-9288.1223

Assadi, N., Murad, T., \& Khalil, M. (2019). Training Teachers' Perspectives of the Effectiveness of the "Academy-Class" Training Model on Trainees' Professional Development. Theory and Practice in Language Studies, 9(2), 137-145. https://doi.org/10.17507/tpls.0902.03

Benitti, F. B. V. (2012). Exploring the educational potential of robotics in schools: A systematic review. Computers \& Education, 58(3), 978-988. https://doi.org/10.1016/j.compedu.2011.10.006

Bernstein, D., Mutch-Jones, K., Cassidy, M., \& Hamner, E. (2020). Teaching with robotics: creating and implementing integrated units in middle school subjects. Journal of Research on Technology in Education, 1-16. https://doi.org/10.1080/15391523.2020.1816864 
Berry, C. A., Remy, S. L., \& Rogers, T. E. (2016). Robotics for All Ages: A Standard Robotics Curriculum for K-16. IEEE Robotics \& Automation Magazine, 23(2), 4046. doi:10.1109/mra.2016.2534240

Bers, M. U. (2008). Blocks to robots: Learning with technology in the early childhood classroom. New York, NY: Teachers College Press.

Briggs, G., \& Scheutz, M. (2014). How robots can affect human behavior: Investigating the effects of robotic displays of protest and distress. International Journal of Social Robotics, 6(3), 343-355.

CEDEFOP \& European Commission. (2016). Guiding principles on professional development of trainers in vocational education and training. Luxembourg: Publications Office of the European Union. Retrieved, 5.

Chang, C. C., \& Chen, Y. (2018). The Impact of an Integrated Robotics STEM Course with a Sailboat Topic on High School Students' Perceptions of Integrative STEM, Interest, and Career Orientation. EURASIA Journal of Mathematics, Science and Technology Education, 14(12). https://doi.org/10.29333/ejmste/94314

Coşkunserçe, O. (2021). Implementing teacher-centered robotics activities in science lessons: The effect on motivation, satisfaction and science skills. Journal of Pedagogical Research, 5(1), 50-64. http://dx.doi.org/10.33902/JPR.2021067231

Darling-Hammond, L., Hyler, M. E., \& Gardner, M. (2017). Effective teacher professional development. Learning Policy Institute.

Datteri, E., Zecca, L., Laudisa, F., \& Castiglioni, M. (2013). Learning to explain: the role of educational robots in science education. Themes in Science and Technology Education, 6(1), 29-38.

DeCoito, I., \& Richardson, T. (2018). Teachers and technology: Present practice and future directions. Contemporary Issues in Technology and Teacher Education, 18(2). https://citejournal.org/volume-18/issue-2-18/science/teachers-and-technologypresent-practice-and-future-directions

Du, G., Wang, Z., \& Li, Z. (2020). A new cloud robots training method using cooperative learning. IEEE Access, 8, 20838-20848.

Eguchi, A. (2017). Bringing Robotics in Classrooms. Robotics in STEM Education, 331. doi:10.1007/978-3-319-57786-9_1

Flores, Vega Rishelline Anne (2006). Effects of using educational robotics at the elementary school level . Theses Digitization Project. 3059. https://scholarworks.lib.csusb.edu/cgi/viewcontent.cgi article $=4095 \&$ context=etdproject

Frangou, S., Papanikolaou, K., Aravecchia, L., Montel, L., Ionita, S., Arlegui, J., Pina, A., Menegatti, E., Moro, M., Fava, N., \& Monfalcon, S. (2008). Representative examples of implementing educational robotics in school based on the constructivist approach. Proceeding of the 2008 conference on simulation, modeling and programming for autonomous robots, (pp. 54-65). 
Gerecke, U., \& Wagner, B. (2007). The Challenges and Benefits of Using Robots in Higher Education. Intelligent Automation \& Soft Computing, 13(1), 2943. doi:10.1080/10798587.2007.10642948

Goh, Henry \& Baharuddin, Aris (2007). Using robotics in education : Lessons learned and learning experiences. 1st International Malaysian Educational Technology Convention.

Gonzales, M., Andal, E., Tabo. E., Ofrin, D., Gaffud, M., Serrano, R. \& Castillo, A. (2020). Training Needs Analysis of K-12 Teachers on Robotics Education: Basis for the Implementation of RoboTeach Extension Project. APCoRE 2020 International Virtual Conference. Asia Pacific Consortium of Researchers and Educators.

Gokcearslan, S., Erdogdu, F., Ozturk, H., \& Alper, A. (2018). An Emerging Topic in Information and Communication Technologies Education: Robotics Education Based On Teachers' Experience and Opinions in Turkey. ISERD International Conference, Manila, $\quad$ Philippines.

ResearchGate, https://www.researchgate.net/publication/323258945

He, Yanna \& Liang, Liying. (2019). Application of Robotics in Higher Education in Industry 4.0 Era. Universal Journal of Educational Research. 7. 1612-1622. 10.13189/ujer.2019.070715.

Iyewa, V. I., \& Gberevbie, D. E. (2017). Staff training and organizational goals attainment: a study of Airtel Nigeria Networks. Covenant University Journal of Politics and International Affairs, 5(1).

Javed, S. M., Muneer, S., \& Anuar, M. A. (2013). Impact of Training on Expectation of Employee and Employer: A comparative study. Information Management and Business Review, 5(12), 601-607.

Jomento-Cruz, Ingrid Lorelei (2010). Robotics as a Means of Increasing Student Achievement in Middle School Science. LSU Master's Theses. 4044. https://digitalcommons.lsu.edu/gradschool_theses/4044

Jones, A. M. (2003). The use and abuse of PowerPoint in Teaching and Learning in the Life Sciences: A Personal Overview. Bioscience Education, 2(1), 1-13.

Kaloti-Hallak, F. (2014, July). The effect of robotics activities on students' learning and attitudes. In Proceedings of the tenth annual conference on International computing education research (pp. 153-154).

Karim, M. E., Lemaignan, S., \& Mondada, F. (2015). A review: Can robots reshape K-12 STEM education? In Proceeding of 2015 IEEE International Workshop on Advanced Robotics and its Social Impacts (ARSO). Lyon, France. https://doi.org/10.1109/ARSO.2015.7428217

Kim, C., Kim, D., Yuan, J., Hill, R. B., Doshi, P., \& Thai, C. N. (2015). Robotics to promote elementary education pre-service teachers' STEM engagement, learning, and teaching. Computers \& Education, 91, 14-31. doi:10.1016/j.compedu.2015.08.005

Kubilinskiene, S., Zilinskiene, I., Dagiene, V., \& Sinkevièius, V. (2017). Applying robotics in school education: A systematic review. Baltic Journal of Modern Computing, 5(1), 50- 69. doi: http://dx.doi.org/10.22364/bjmc.2017.5.1.04

Leeuw, Frans (2009). Impact Evaluations and Development. NONIE Guidance on Impact Evaluation. Independent Evaluation Group. https://www.oecd.org/development/evaluation/dcdndep/47466906.pdf 
López-Belmonte, J., Segura-Robles, A., Moreno-Guerrero, A. J., \& Parra-González, M. E. (2021). Robotics in Education: A Scientific Mapping of the Literature in Web of Science. Electronics, 10(3), 291. https://doi.org/10.3390/electronics10030291

Miller D.P., \& Nourbakhsh I. (2016) Robotics for Education. In: Siciliano B., Khatib O. (eds) Springer Handbook of Robotics. Springer Handbooks. Springer, Cham. https://doi.org/10.1007/978-3-319-32552-1_79

Montemayor, M. T. \& Sevilla (2018, July 8). Why include robotics in PH school curriculum. Philippine News Agency. https://www.pna.gov.ph/articles/1040784

Mouhamad, Abdelrahim el (2019). Educational Robotics is a Useful Tool in Education. https://www.researchgate.net/publication/332401229

Nall, Mark. (2016). "Robotics in the classroom: The effectiveness of robotics based curriculum in STEM education. UNI ScholarWorks. Graduate Research Paper.88 https://scholarworks.uni.edu/cgi/viewcontent.cgi?article=1088\&context=grp

Negrini, L. (2018). Teacher Training in Educational Robotics. Advances in Intelligent Systems and Computing, 92-97. doi:10.1007/978-3-319-97085-1_10

Newton, D. P., \& Newton, L. D. (2019). Humanoid Robots as Teachers and a Proposed Code of Practice. Frontiers in Education, 4. https://doi.org/10.3389/feduc.2019.00125

Ntemngwa, C. \& Oliver, J.S. (2018). The Implementation of Integrated Science Technology, Engineering and Mathematics (STEM) Instruction using Robotics in the Middle School Science Classroom. International Journal of Education in Mathematics, Science and Technology (IJEMST), 6(1), 12-40. DOI:10.18404/ijemst.380617

Nurbekova, Z. K., Mukhamediyeva, K. M., Davletova, A. H., \& Kasymova, A. H. (2018). Methodological system of educational robotics training: Systematic literature review. Espacios, 39(15), 28-28.

OECD (2008). New millennium learners: a project in progress optimising learning: implications of learning sciences research. www.oecd.org/dataoecd/39/51/40554230.pdf

Oludeyi, Olukunle. (2018). The Importance of Feedback System in Training Programmes: An Empirical Investigation. 2.

Ospennikova, E., Ershov, M., \& Iljin, I. (2015). Educational robotics as an inovative educational technology. Procedia-Social and Behavioral Sciences, 214, 18-26.

Papadakis, S.; Vaiopoulou, J.; Sifaki, E.; Stamovlasis, D.; Kalogiannakis, M. (2021). Attitudes towards the Use of Educational Robotics: Exploring Pre-Service and InService Early Childhood Teacher Profiles. Educ. Sci. 11, 204. https://doi.org/10.3390/educsci11050204

PBOT 2018 Entry Level Mobile Robot Controller - Introduction. (n.d.). www.e-Gizmo.Net. Retrieved August 14, 2021, from https://www.egizmo.net/oc/index.php?route=journal3/blog/post\&journal_blog_post_id=31

Peersman, G. (2015). Impact evaluation. Better Evaluation. https://www.betterevaluation.org/themes/impact_evaluation

Pentang, J.T. (2021). Impact Assessment and Clients' Feedback towards MATHEMATICS Project Implementation. International Journal of Educational Management and Development Studies, Volume 2, Issue 2, pp. 90 - 103.

Sahin, G., Funda, E. \& Ayfer, A. (2018). An Emerging Topic in Information and Communication Technologies Education: Robotics Education Based On 
Teachers' Experience and Opinions in Turkey, ResearchGate, ISERD International Conference, Manila, Philippines.

Sánchez, H., Martínez, L. S., \& González, J. D. (2019). Educational Robotics as a Teaching tool in higher education institutions: A bibliographical analysis. Journal of Physics: Conference Series, 1391, 012128. https://doi.org/10.1088/1742-6596/1391/1/012128

Scaradozzi, D., Sorbi, L., Pedale, A., Valzano, M., \& Vergine, C. (2015). Teaching robotics at the primary school: an innovative approach. Procedia-Social and Behavioral Sciences, 174, 3838-3846. https://doi.org/10.1016/j.sbspro.2015.01.1122

Schina, D., Esteve-González, V., \& Usart, M. (2020). An overview of teacher training programs in educational robotics: characteristics, best practices and recommendations. Education and Information Technologies, 26(3), 2831-2852. https://doi.org/10.1007/s10639-020-10377-z

Sergeyev, A., \& Alaraje, N., \& Kuhl, S. A., \& Highum, M., \& Kinney, M. B., \& Walker, J. (2016, June), Revamping Robotics Education via University, Community College and Industry Partnership - Year 1 Project Progress Paper presented at 2016 ASEE Annual Conference \& Exposition, New Orleans, Louisiana. 10.18260/p.27340

Shehata, A., \& Strömbäck, J. (2013). Not (yet) a new era of minimal effects: A study of agenda setting at the aggregate and individual levels. The International Journal of Press/Politics, 18(2), 234-255.

Tallis. (2009). Creating Effective Teaching and Learning Environments: First Results (Chapter 4: Teaching Practices, Teachers' Beliefs And Attitudes ed.). OECD. https://www.oecd.org/berlin/43541655.pdf

The Top Five Unexpected Benefits of Robotics in the Classroom. (2016, December 24). Getting Smart. https://www.gettingsmart.com/2016/11/unexpected-benefits-roboticsin-the-classroom/

Thomaz, S., Aglae, A., Fernandes, C., Pitta, R., Azevedo, S., Burlamaqui, A., Silva, A., \& Goncalves, L. M. G. (2009). RoboEduc: A pedagogical tool to support educational robotics. 2009 39th IEEE Frontiers in Education Conference. Published. https://doi.org/10.1109/fie.2009.5350439

U.S. Department of education. (2017). Reimagining the Role of Technology in Education. Http://Tech.Ed.Gov. https://tech.ed.gov/files/2017/01/NETP17.pdf

Usman, Yunusa Dangara. (2016). Educational Resources: An Integral Component for Effective School Administration in Nigeria. Research on Humanities and Social Sciences, 6(13). https://files.eric.ed.gov/fulltext/ED578024.pdf

Williams, D. C., Ma, Y., Prejean, L., Ford, M. J., \& Lai, G. (2007). Acquisition of physics content knowledge and scientific inquiry skills in a robotics summer camp. Journal of Research on Technology in Education, 40(2), 201-216.

Wisshak, S., \& Hochholdinger, S. (2018). Trainers' knowledge and skills from the perspective of trainers, trainees and human resource development practitioners. International Journal of Training Research, 16(3), 218-231.

Ziaeefard, S., Miller, M. H., Rastgaar, M., \& Mahmoudian, N. (2017). Co-robotics hands-on activities: A gateway to engineering design and STEM learning. Robotics and Autonomous Systems, 97, 40-50. 